\title{
EVAPOTRANSPIRATION IN RELATION TO SOIL MOISTURE
}

\author{
R. O. SLATYER \\ Land Research and Regional Survey Section, C.S.I.R.O., \\ Canberra, A.C.T., Australia
}

\section{SUMMARY}

Data are presented from an experiment conducted in northern Australia, in which the water balance between soil, plant, and atmosphere was studied in relation to crops of cotton, peanuts and grain sorghum.

The data illustrate the progressive decline in actual evapotranspiration which occurred as the amount of available soil moisture decreased.

\section{INTRODUCTION}

Since 1950, a unit of the Land Research and Regional Survey Section of C.S.I.R.O. has been engaged in climatological research in the monsoon zone of northern Australia. The unit has been concerned mainly with studies of the water balance between soil, plant, and atmosphere in relation to different environmental conditions and different types of plant cover, so that a considerable amount of evapotranspiration data is gradually accumulating for different plants grown under a range of soil and atmospheric conditions.

The monsoon zone of Australia has a climate characterized by sharply defined wet and dry seasons of about four and eight months duration respectively. During the wet season the rainfall is very intermittent in nature so that groups of several consecutive rainy days may be interspersed by periods of dry weather of two or more weeks. As a result of these seasonal and intraseasonal rainfall characteristics, it is to be expected that symptoms of water stress frequently appear in plants, and evapotranspiration rates are markedly reduced.

Because of these features interest has been focussed on actual evapotranspiration much more than potential evapotranspiration, and in this paper data are presented to demonstrate the influence of decreasing soil moisture on the progressive reduction of evapotranspiration below potential levels.

\section{EXPERIMENTAL DETAILS}

The experiment from which these data have been obtained was a field experiment in which crops of cotton (Gossypium hirsutum, var. Miller 43-9-0), peanuts (Arachis hypogea, var. Virginia Bunch) and grain sorghum (Sorghum vulgare, var. Kalo) were grown in a replicated layout. Measurements were made of climatic conditions, of changes in soil moisture status, and of plant response in terms of growth, transpiration, and leaf turgor. The experiment has been fully described in a separate paper (Slatyer, 1955) but an outline will be given here of the measurements relevant to this paper.

Evapotranspiration was determined by measuring changes in soil moisture status. For this purpose a comprehensive installation of gypsum blocks was 
employed and additional information obtained by direct soil sampling with augers. The blocks, which were of the Bouyoucos and MICK (1940) pattern were installed at depths of $8,16,24,32,48$, and 64 inches, and were placed directly under the crop rows and the centre of the inter-row spaces. Duplicates were installed at each depth in each of the six replications of each crop.

In general the installation procedure closely followed the pattern of AIтcHISON, BuTLER, and GuRR (1951), as did the block resistance-moisture tension and resistence-moisture content calibrations required for the interpretation of the block readings.

Block readings were made twice weekly and at other times when considered necessary. Soil temperature determinations were made by means of thermistors placed at each depth of block installation and the block resistances corrected for temperature changes by the equation of SLATER and Bryant (1946). For the 0-8 in. horizon, auger samples were obtained at the same time and were oven-dried to constant weight to obtain gravimetric estimates of water content. Further auger determinations were made following each fall of rain to determine depth of water penetration.

From the appropriate calibrations a picture of changes in soil moisture status throughout the season was obtained. The soil moisture content at any sampled depth was estimated as the mean of the row and inter-row determinations. For the evaluation of the amount of water in the profile on any one occasion the mean values obtained as above were assumed to represent the moisture contents midway between the adjacent points; that is, the 16 in. value was assumed to represent the moisture content of the $12-20$ in. zone, and the $24 \mathrm{in}$. value the content of the 20-28 in. zone. Losses in the 0-8 in. horizon were estimated from the auger determinations, as were the other slight losses which, during the period of the experiment, occurred in all soil zones beyond the sensitive limits of the gypsum blocks.

With this information, together with rainfall data, it has been possible to construct a water balance sheet between intake and loss, and so to compute evapotranspiration on a day to day basis.

In the accompanying Figure 1 this data has been plotted against available soil moisture as the ratio of actual evapotranspiration to potential evapotranspiration. The data have been taken from a part of the season when an unusually long (about five weeks) period of dry weather followed several days of heavy rain, and soil moisture reserves were seriously depleted.

The absence of some meteorological observations precluded the use of formulae such as PenMan's (1948) for estimating potential evapotranspiration, so recourse was made to an established formula developed by Prescotr (1949a, $1949 \mathrm{~b}$ ) which relates evapotranspiration to evaporation from a free water surface, by an expression of the form

$$
E t=k \cdot E w^{0.75}
$$

where $E t=$ evapotranspiration in inches per month and $E w=$ evaporation in inches per month from a standard $3 \mathrm{ft}$. diameter tank evaporimeter. For the potential evapotranspiration of normal actively growing vegetation, amply supplied with soil moisture Butlen and Prescott (1955) have shown the value of $k$ to be of the order of $1.8-2.1$. 


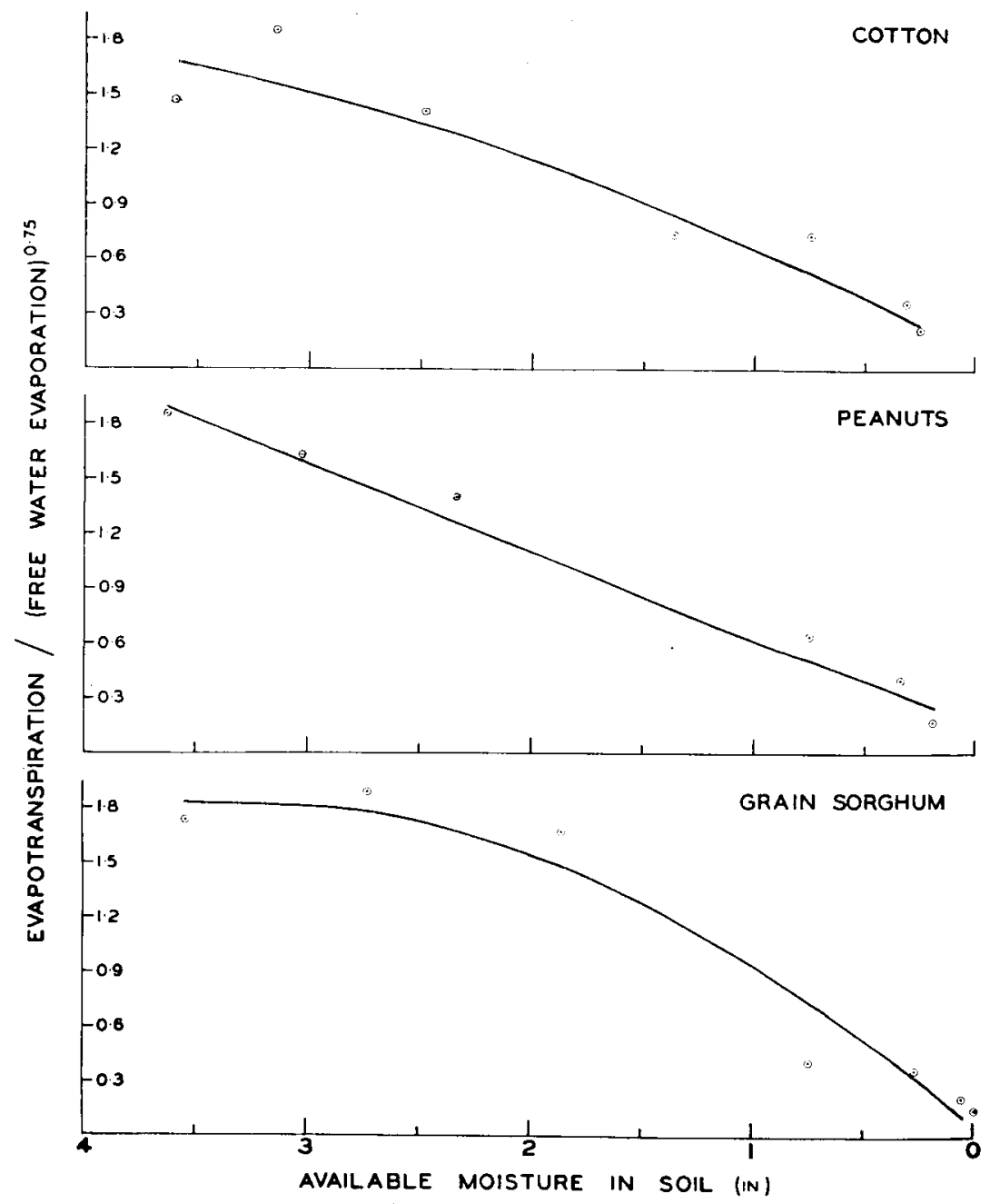

Fig. 1. Evapotranspiration devided by free water transpiration to the powel 0.75 aS A FUNCTION OF SOIL MOISTURE FOR THREE CROPS.

\section{Results AND DISCUSSION}

From Figure 1 it is at once evident that a progressive decline in actual relative to potential evapotranspiration occurred as the amount of available soil moisture decreased. In each crop the initial values of evapotranspiration were approximately equal to potential levels, according to the Prescotr formula. The shape of the curves are generally similar, but slight differences do exist and it is of interest to examine these in the light of the responses of the different crops to moisture stress.

In grain sorghum evapotranspiration was maintained at a high level for some time, whereas in cotton and peanuts a decline started almost as soon as soil moisture depletion commenced, and continued at a fairly constant rate.

This was attributed by SLATYER (loc. cit.) mainly to the more extensive root system of grain sorghum which provided this crop with ready access to most 
of the wetted volume of soil, and also to its greater ability to withstand atmospheric desiccation. These features enabled the maintenance of a satisfactory water balance in the tissues, and consequently the maintenance of normal plant functions, until fairly severe soil moisture stress existed.

Cotton and peanuts, besides having a less extensive and efficient root system than grain sorghum, were also less able to withstand atmospheric stress, and as a result their internal water balance deteriorated rapidly with the onset of dry weather. This resulted in a steady reduction in growth rate and general activity of both crops with an associated decrease in transpiration.

The point indicating zero available moisture in Figure 1 represented the amount of moisture remaining in the soil at the conclusion of the general experiment, which was several weeks after the end of the period of dry weather represented in the Figure. This minimum point was slightly lower, in the upper soil horizons, than the amount of moisture retained by the soil at 15 atmospheres tension. It may be of interest to mention that in other experiments in which plants have been left in the field during the dry season, the final soil moisture contents are frequently appreciably below the 15 atmosphere figures.

\section{REFERENCES}

Artchison, G. D., P. F. Butler, and C. G. Gurr: Techniques associated with the use of gypsum block soil moisture meters. Australian J. Appl. Sci. 2 (1951) 56-75.

BouYoucos, G. I. and A. H. Mick: An electrical resistance method for the continuous measurement of soil moisture under field conditions. Michigan Agr. Exp. Sta. Tech. Bull. 172 (1940).

Butler, P. F. and J. A. Prescott : Evapotranspiration from wheat and pasture in relation to available moisture. Australian J. Agric. Res. 6 (1955) 52-61.

Penman, H. L.: Natural evaporation from open water, bare soil and grass. Proc. Roy. Soc. A. 193 (1948) 120-146.

Phescotr, J. A. : A climatic index for the leaching factor in soil formation. J. Soil Sci. 1 (1949a) 9-19.

- - : Climatic expressions and generalized climatic zones in relation to soils and vegetation. Proceedings Specialist Conference in Agriculture, Australia (1949b).

Slater, C. S. and J. C. Bryant : Comparison of four methods of soil moisture measurement. Soil Sci. 61 (1946) 131-155.

Slatyen, R. O.: Studies of the water relations of crop plants grown under natural rainfall in northern Australia. Australian J. Agric. Res. 6 (1955) 365-377. 